Original Research Article

\title{
Knowledge, attitude and practice regarding voluntary blood donation among Mawlana Bhashani Science and Technology University students in Bangladesh
}

\author{
Md. Imam Hossain*, Nilufar Easmin, Shafiqur Rahman, Meskatul Islam, Abdus Salam
}

\begin{abstract}
Department of Biotechnology and Genetic Engineering, Mawlana Bhashani Science and Technology University, Santosh, Tangail-1902, Bangladesh
\end{abstract}

Received: 30 May 2018

Accepted: 26 June 2018

\section{*Correspondence to:}

Dr. Md. Imam Hossain, Email: imubcmb@gmail.com

Copyright: (C) the author(s), publisher and licensee Medip Academy. This is an openaccess article distributed under the terms of the Creative Commons Attribution NonCommercial License, which permits unrestricted noncommercial use, distribution, and reproduction in any medium, provided the original work is properly cited.

\begin{abstract}
Background: In developing countries like Bangladesh, the demand of blood supply is increasing every year. To ensure safe and adequate blood supply and to motivate voluntary donors in blood donation processes, this study was aimed to assess the knowledge, attitude and practice of blood donation among Mawlana Bhashani Science and Technology University students in Bangladesh.

Methods: A cross-sectional study was conducted among 403 students (200 females and 203 males), using a self administered structured questionnaire.

Results: $59.05 \%$ students had good knowledge about blood donation. The knowledge score was significantly higher $(\mathrm{p}<0.05)$ in female than male. Students positive attitudes toward voluntary blood donation included- blood donation saves life (62.8\% strongly agreed, $32 \%$ agreed), donation is a moral activity (57.1\% strongly agreed, $37.5 \%$ agreed), young are more suitable to donate blood (40\% strongly agreed, $49.1 \%$ agreed), the best way of donation is voluntary nonremunerated $(22.3 \%$ strongly agreed, $41.4 \%$ agreed). Their negative attitudes included - best way to donate blood is at the request of relatives $(24.3 \%$ strongly agreed, $38 \%$ agreed), donation in paid (only 3\% strongly agreed, 10.7\% agreed) or something in exchange (only 1\% strongly agreed, $8.9 \%$ agreed) and blood donors contract disease (3.5\% strongly agreed, $27.8 \%$ agreed). Among the participants $34.2 \%$ donated blood and males donated significantly more than females $(\mathrm{p}<0.001)$. Physically females were significantly unfit for donating blood $(\mathrm{p}<0.001)$.
\end{abstract}

Conclusions: Although having positive attitudes blood donation practice is not substantial among students especially in females. Interactive awareness and motivation packages should be created to enhance voluntary blood donation.

Keywords: Attitude, Bangladesh, Blood donation, Knowledge, Practice

\section{INTRODUCTION}

In modern healthcare services blood transfusion is one of the key lifesaving component which is being routinely used in medical emergency situation such as in gynecological conditions, pregnancy and childbirth, severe childhood illness, anemia, trauma and cancers or medical hematological conditions. ${ }^{1}$ In developing countries as well as in developed countries, demand of blood and blood products is increasing by every year.
However, blood donation does not match with the increasing demands. ${ }^{2}$ On average, high income countries have 9 times higher donation rate compared to low income countries. ${ }^{3}$ During the last few decades, the number of active blood donors was decreased and couldn't meet the increased demands for blood transfusion. Also, most of donors are involuntary who came only for their relatives or friends and paid donors while those who usually donate are few. ${ }^{4}$ Ignorance, fear and misconcepts about blood donations and lack of voluntary blood donation 
organizations are major constraints in many developing countries to facilitate voluntary blood donation.

The blood supply is usually insufficient in some regions of the world i.e. none of the least developed countries (LDCs) and $9 \%$ of the developing countries (DGCs) collect 30 units or more per 1,000 of the population annually. Blood donor systems are totally voluntary and non-remunerated in $15 \%$ DGCs and 7\% LDCs; $80 \%$ DGCs and 93\% LDCs rely totally or partially on replacement donors and $25 \%$ of both groups on paid donations. ${ }^{5}$

According to Directorate General of Health Services of Bangladesh there is a demand of 80 lakhs unit of blood per year of which only $25 \%$ come from voluntary donation, $20-25 \%$ from paid donors, and 50-55\% from one-time donation for a specific patient. ${ }^{6}$ In recent years the country has seen a rise in voluntary and direct donation of blood, it still lags well behind demand. To meet the demands the recipients depends on professional donors who mostly contribute to unsafe blood transfusions. To ensure safe blood, the rate of voluntary blood donation is yet to increase.

For motivating voluntary donors to be engaged regularly in blood donation processes, it is essential to study their general knowledge about blood donation and their views and attitudes. The global burden of diseases due to unsafe blood transfusion can be eliminated or substantially reduced by adopting an integrated strategy for blood safety. Though awareness among donors about blood donation is an important issue, but very few studies have done yet in Bangladesh about this issue. Identification of the negative attitudes about blood donation, the motivational factors that may encourage blood donation, and general knowledge about blood donation would facilitate and improve the process of blood donation and help to decrease the gap between the increasing demands and the stationary inadequate supply among different nations.

According to WHO, an estimated $38 \%$ of reported voluntary blood donations are contributed by people under the age of 25. WHO also insist countries to focus on young people to achieve 100 per cent voluntary unpaid blood donation. $^{7}$ Young students are healthy, active, dynamic and receptive and constitute a greater proportion of population. They have to be encouraged, inspired and motivated to donate blood voluntarily. Considering the importance and significance of student community in voluntary blood donation this study has carried out to understand knowledge, attitude and practice about blood donation among students of a public university of Bangladesh.

\section{METHODS}

For the study, Institutional permission was taken from the Department of Biotechnology and Genetic Engineering (BGE) of Mawlana Bhashani Science and Technology
University (MBSTU), Bangladesh. The students who participated in this study have given their written approval and all sorts of confidentialities and rights of the study subjects were stringently maintained.

\section{Study design and selection of study subjects}

This human population based cross-sectional epidemiological study was conducted from March 2018 to April 2018. For the study 403 students (200 were female and 203 were male) from all 15 Departments (BGE, FTNS, ESRM, BMB, PHARM, CPS, CSE, ICT, TE, ECO, BBA, PHY, CHE, MATH and STAT) of Mawlana Bhashani Science and Technology University (MBSTU), Tangail 1902, Bangladesh were selected by simple random sampling method.

\section{Preparation of questionnaire}

A self-administered, well-structured and validated questionnaire was used to asses Knowledge, Attitude and Practice (KAP) of blood donation. The structured questionnaire was adapted after a review of different literatures. ${ }^{8-11}$ Questionnaire was consisted of four sections; Knowledge, Positive attitude, Negative attitude and Practice of blood donation. Section 1 of the questionnaire included the questions to assess the knowledge of blood donation of the participants. This section included a person can be infected by receiving blood or not, what diseases can be transmitted by blood transfusion, how often an individual can donate, who can donate blood, what volume of blood can be donated at a session, what the duration of donation process is, the minimum volume of blood to be donated, and the minimum hemoglobin for blood donation in men and women. The section 2 of the questionnaire included the negative attitudes of university students towards blood donation such as requesting blood donation from relatives, paid blood donations, compensations for blood donors, belief that blood donors are vulnerable to infections, belief that blood donation can weaken donors, and donating blood to get free investigations. The section 3 of the questionnaire included questions about positive attitudes among university students about blood donations such as beliefs that blood donation may save people lives, and is considered a moral activity, beliefs that young people should frequently donate blood more than elderly, and that the best way to donate blood is voluntary non-remunerated and that every person should always disclose correct information about their health before donating blood. Lastly, the section 4 of the questionnaire included questions about their previous practice of blood donation, their satisfaction about that, being unfit to donate, their need to donate for friends or relatives, fear of needles, fear of knowing their status, selling donated blood, and donating blood without monetary exchange.

Demographic information of the study individuals including name, age, sex, marital status, etc. were also collected. 


\section{Data collection}

Surveys were conducted by student representatives. The survey package contained a cover letter and a questionnaire in English version. The survey has been handed to each student to read and decide whether to participate or not.

\section{Data processing and analysis}

Statistical analyses for the study were performed using the Statistical Packages for Social Sciences (SPSS Statistics for Windows, Version 21.0. Armonk, NY: IBM Corp) software. Frequencies of basic demographic characteristics such as department wise distribution, age, sex, blood group and marital status of the study participants were calculated using appropriate descriptive and statistical tests such as proportion, mean, standard deviation, Pearson chi-square tests etc. The overall knowledge about voluntary blood donation was assessed using a scoring system as described by Urgesa et al. ${ }^{12}$ For every question of the knowledge section (11 questions total) a score of 1 was given to correct responses, and 0 was used for incorrect/do not know responses. Mean value was used to categorize the study participants into two categories. Scores less than the mean value were considered as poor knowledge, while scores greater than the mean value were considered as good knowledge. Negative and positive attitude of the study participants toward blood donation were assessed using questionnaire in two different sections. Each section comprised of six questions and each question had five alternatives (strongly agree, agree, neutral, disagree and strongly disagree). Frequency $\mathrm{n}(\%)$ of the results were analyzed for female and male study participants. Practice related to blood donation both in male and female were also calculated by appropriate statistical tests.

\section{RESULTS}

\section{Descriptive characteristics of the study participants}

Table 1 shows the descriptive characteristics of the study participants. The study included total 403 student from all 15 departments of Mawlana Bhashani Science and Technology University, Bangladesh among which 200 were female and 203 were male students. The age range of the students were 19 to 28 and mean age was $23.18 \pm 1.37$ years. Almost all students knew their own blood group and about eight types of common blood groups. The male study participants were almost unmarried and $10 \%$ female participants were married.

Figure 1 shows the distribution of blood group among female and male study participants. The results showed that, in female highest number of participants had B positive blood group (45.2\%). Next came were $\mathrm{O}$ positive $(41.5 \%), \mathrm{A}$ positive $(23.5 \%), \mathrm{AB}$ positive $(7 \%), \mathrm{O}$ negative $(1 \%), \mathrm{AB}$ negative $(0.5 \%)$ and $\mathrm{B}$ negative $(0.5 \%)$. No female student had A negative blood group. In case of male students, highest number of students had B positive blood group (31\%) and next came were $\mathrm{O}$ positive (30.5\%), A positive (21.2\%), AB positive (11.8\%), O negative (2.5\%), B negative (2\%), A negative (0.5) and AB negative $(0.5 \%)$.

Table 1: Basic demographic characteristics of participants.

\begin{tabular}{|c|c|c|c|c|c|c|c|}
\hline \multirow{2}{*}{\multicolumn{3}{|c|}{ Variables }} & \multicolumn{2}{|c|}{ Female } & \multicolumn{2}{|c|}{ Male } & \multirow{2}{*}{$\begin{array}{l}\text { Total } \\
\text { (n) }\end{array}$} \\
\hline & & & n & $\%$ & n & $\%$ & \\
\hline \multirow{16}{*}{ อِّ } & \multicolumn{2}{|c|}{ BBA } & 9 & 40.9 & 13 & 59.1 & 22 \\
\hline & \multicolumn{2}{|c|}{ BGE } & 24 & 45.3 & 29 & 54.7 & 53 \\
\hline & \multicolumn{2}{|c|}{$\mathrm{BMB}$} & 12 & 75 & 4 & 25 & 16 \\
\hline & \multicolumn{2}{|c|}{$\mathrm{CHE}$} & 16 & 48.5 & 17 & 51.5 & 33 \\
\hline & \multicolumn{2}{|c|}{ CPS } & 18 & 60 & 12 & 40 & 30 \\
\hline & \multicolumn{2}{|c|}{ CSE } & 6 & 40 & 9 & 60 & 15 \\
\hline & \multicolumn{2}{|c|}{ ECO } & 16 & 57.1 & 12 & 42.9 & 28 \\
\hline & \multicolumn{2}{|c|}{ ESRM } & 17 & 63 & 10 & 37 & 27 \\
\hline & \multicolumn{2}{|c|}{ FTNS } & 19 & 42.2 & 26 & 57.8 & 45 \\
\hline & \multicolumn{2}{|c|}{ ICT } & 9 & 42.9 & 12 & 57.1 & 21 \\
\hline & \multicolumn{2}{|c|}{ MATH } & 12 & 63.2 & 7 & 36.8 & 19 \\
\hline & \multicolumn{2}{|c|}{ PHARM } & 7 & 50 & 7 & 50 & 14 \\
\hline & \multicolumn{2}{|c|}{ PHY } & 13 & 65 & 7 & 35 & 20 \\
\hline & \multicolumn{2}{|c|}{ STAT } & 13 & 39.4 & 20 & 60.6 & 33 \\
\hline & \multicolumn{2}{|c|}{$\mathrm{TE}$} & 9 & 33.3 & 18 & 66.7 & 27 \\
\hline & \multicolumn{2}{|c|}{ Total (n) } & \multicolumn{2}{|l|}{200} & \multicolumn{2}{|c|}{203} & 403 \\
\hline \multicolumn{3}{|c|}{ Age (Mean士SD) } & \multicolumn{2}{|c|}{$23.20 \pm 1.25$} & \multicolumn{2}{|c|}{$23.16 \pm 1.49$} & $23.18 \pm 1.37$ \\
\hline \multirow{2}{*}{\multicolumn{2}{|c|}{$\begin{array}{l}\text { Marital } \\
\text { status }\end{array}$}} & Yes & 20 & 10 & 1 & 0.5 & 20 \\
\hline & & No & 180 & 90 & 202 & 99.5 & 383 \\
\hline \multirow{2}{*}{\multicolumn{2}{|c|}{$\begin{array}{l}\text { Blood } \\
\text { group }\end{array}$}} & Known & 200 & 100 & 203 & 100 & 403 \\
\hline & & $\begin{array}{l}\text { Un- } \\
\text { known }\end{array}$ & 0 & 0 & 0 & 0 & 0 \\
\hline
\end{tabular}

$\mathrm{n}=$ number of study participants; $\mathrm{SD}=$ Standard Deviation. $\mathrm{BBA}=$ Bachelor of Business Administration; BGE= Biotechnology and Genetic Engineering; $\mathrm{BMB}=$ Biochemistry and Molecular Biology; $\mathrm{CHE}=$ Chemistry; $\mathrm{CPS}=$ Criminology and Police Science; $\mathrm{CSE}=$ Computer Science and Engineering; $\mathrm{ECO}=$ Economics; ESRM= Environmental Science and Resource Management; FTNS= Food Technology and Nutritional Science; ICT= Information and Communication Technology; MATH= Mathematics; PHARM= Pharmacy; $\mathrm{PHY}=$ Physics; STAT= Statistics; TE $=$ Textile Engineering.

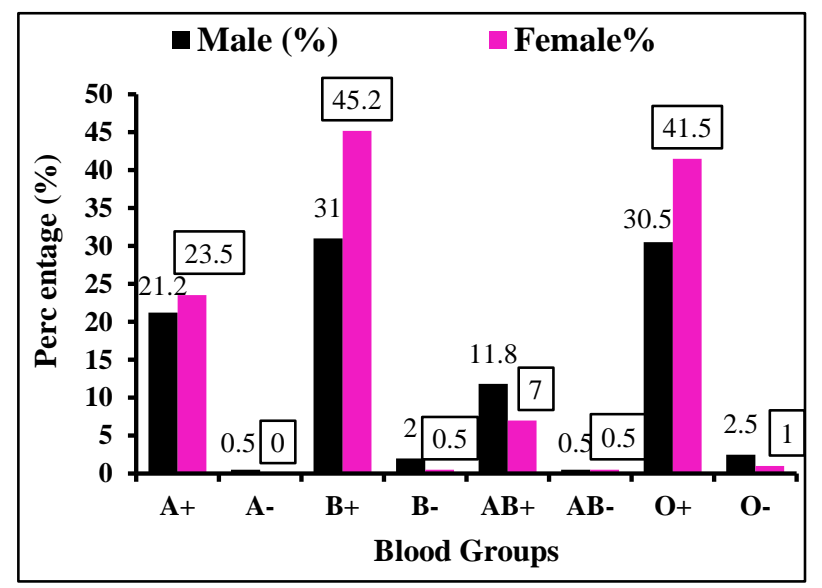

Figure 1: Distribution of blood group among male and female study participants. 
Table 2: Level of knowledge of blood donation between female and male students of MBSTU.

\begin{tabular}{|c|c|c|c|c|c|c|c|c|}
\hline \multirow{2}{*}{ Variables } & \multicolumn{2}{|c|}{ Female } & \multicolumn{2}{|c|}{ Male } & \multicolumn{2}{|c|}{ Total } & \multirow{2}{*}{$x^{2}$} & \multirow{2}{*}{ p value } \\
\hline & $\mathbf{n}$ & $\%$ & $\mathbf{n}$ & $\%$ & $\mathbf{n}$ & $\%$ & & \\
\hline \multicolumn{9}{|c|}{ Level of knowledge } \\
\hline Good & 129 & 64.5 & 109 & 53.7 & 238 & 59.05 & \multirow{2}{*}{4.865} & \multirow{2}{*}{$<0.05^{\mathrm{a}}$} \\
\hline Poor & 71 & 35.5 & 94 & 46.3 & 165 & 40.95 & & \\
\hline
\end{tabular}

${ }^{a}$ Significantly different between female and male groups

Table 3: Negative attitude towards blood donation of MBSTU students.

\begin{tabular}{|c|c|c|c|}
\hline \multirow[b]{2}{*}{ Variables } & \multicolumn{3}{|c|}{ Responders sex } \\
\hline & $\begin{array}{l}\text { Female n } \\
(\%)\end{array}$ & $\begin{array}{l}\text { Male n } \\
(\%)\end{array}$ & $\begin{array}{l}\text { Total n } \\
(\%)\end{array}$ \\
\hline \multicolumn{4}{|c|}{$\begin{array}{l}\text { Q1: In my opinion the best way to donate blood is at the } \\
\text { request of relatives }\end{array}$} \\
\hline Strongly agree & $42(21)$ & $56(27.6)$ & $98(24.3)$ \\
\hline Agree & $68(34)$ & $85(41.9)$ & $153(38)$ \\
\hline Neutral & $30(15)$ & $26(12.8)$ & $56(13.9)$ \\
\hline Disagree & $37(18.5)$ & $20(9.9)$ & $57(14.1)$ \\
\hline Strongly Disagree & $23(11.5)$ & $16(7.9)$ & $39(9.7)$ \\
\hline \multicolumn{4}{|c|}{$\begin{array}{l}\text { Q2: In my opinion the best way to donate blood is paid } \\
\text { donation. }\end{array}$} \\
\hline Strongly agree & $3(1.5)$ & $9(4.4)$ & $12(3)$ \\
\hline Agree & $23(11.5)$ & $20(9.9)$ & $43(10.7)$ \\
\hline Neutral & $28(14)$ & $30(14.8)$ & $58(14.4)$ \\
\hline Disagree & $77(38.5)$ & $71(35)$ & $148(36.7)$ \\
\hline Strongly Disagree & $69(34.5)$ & $73(36)$ & $142(35.2)$ \\
\hline \multicolumn{4}{|c|}{$\begin{array}{l}\text { Q3: I think who donate blood should receive something } \\
\text { in exchange. }\end{array}$} \\
\hline Strongly agree & $2(1)$ & $2(1)$ & $4(1)$ \\
\hline Agree & $20(10)$ & $16(7.9)$ & $36(8.9)$ \\
\hline Neutral & $35(17.5)$ & $49(24.1)$ & $84(20.8)$ \\
\hline Disagree & $68(34)$ & $60(29.6)$ & $128(31.8)$ \\
\hline Strongly disagree & $75(37.5)$ & $76(37.4)$ & $151(37.5)$ \\
\hline \multicolumn{4}{|c|}{ Q4: I think who donate blood can contract disease. } \\
\hline Strongly agree & $6(3)$ & $8(3.9)$ & $14(3.5)$ \\
\hline Agree & $64(32)$ & $48(23.6)$ & $112(27.8)$ \\
\hline Neutral & $35(17.5)$ & $42(20.7)$ & $77(19.1)$ \\
\hline Disagree & $68(34)$ & $68(33.5)$ & $136(33.7)$ \\
\hline Strongly disagree & $27(13.5)$ & $37(18.2)$ & $64(15.9)$ \\
\hline \multicolumn{4}{|c|}{ Q5: I think who donate blood are temporarily weakened. } \\
\hline Strongly agree & $13(6.5)$ & $9(4.4)$ & $22(5.5)$ \\
\hline Agree & $121(60.5)$ & $92(45.3)$ & $213(52.9)$ \\
\hline Neutral & $23(11.5)$ & $34(16.7)$ & $57(14.1)$ \\
\hline Disagree & $35(17.5)$ & $52(25.6)$ & $87(21.6)$ \\
\hline Strongly disagree & $8(4)$ & $16(7.9)$ & $24(6)$ \\
\hline \multicolumn{4}{|c|}{ Q6: I donate blood to get free investigations. } \\
\hline Strongly agree & $2(1)$ & $16(7.9)$ & $18(4.5)$ \\
\hline Agree & $43(21.5)$ & $50(24.6)$ & $93(23.1)$ \\
\hline Neutral & $77(38.5)$ & $57(28.1)$ & $134(33.3)$ \\
\hline Disagree & $55(27.5)$ & $59(29.1)$ & $114(28.3)$ \\
\hline Strongly disagree & $23(11.5)$ & $21(10.3)$ & $44(10.9)$ \\
\hline
\end{tabular}

\section{Level of knowledge of blood donation of MBSTU students}

As regards knowledge about blood donation, students were asked about the possibility of infection transmission through the process of blood donation, the infectious diseases that can be transmitted, the frequency of allowed blood donations, the group of individuals who can donate, the volume of blood that can be donated, and the minimum hemoglobin level accepted for an individual to donate blood. The overall knowledge about voluntary blood donation was assessed using a scoring system as described by Urgesa et al. ${ }^{12}$ Table 2 shows the levels of knowledge of blood donation among male and female students of MBSTU. Among the students total $59.05 \%$ had good knowledge on blood donation. It was observed that $64.5 \%$ $(n=129)$ female students had good knowledge about blood donation and $35.5 \%(n=71)$ had poor knowledge of blood donation. Among male students 53.7\% ( $n=109)$ had good knowledge about blood donation and $46.3 \%(n=94)$ had poor knowledge of blood donation. The knowledge score was significantly higher $(\chi 2=4.865 ; \mathrm{p}<0.05)$ in female than male students.

\section{Negative attitude towards blood donation}

Table 3 demonstrates the negative attitudes of female and male study participants about blood donation. The analyses showed that $24.3 \%$ students (female $21 \%$ and male $27.6 \%$ ) strongly agreed and $38 \%$ (female $34 \%$ and male $41.9 \%$ ) agreed that the best way to donate blood is at request of relatives. A small proportion (3\%) of students (female $1.5 \%$ and male $4.4 \%$ ) strongly agreed and $10.7 \%$ (female $11.5 \%$ and male $9.9 \%$ ) agreed that the best way to donate blood is paid donation.

Only $1 \%$ students (female $1 \%$ and male $1 \%$ ) strongly agreed and $8.9 \%$ (female $10 \%$ and male $7.9 \%$ ) agreed that receive something in exchange for their donation. $3.5 \%$ students (female $3 \%$ and male $3.9 \%$ ) strongly agreed and $27.8 \%$ (female $32 \%$ and male $23.6 \%$ ) agreed that blood donors can contract disease. $5.5 \%$ students (female $6.5 \%$ and male $4.4 \%$ ) strongly agreed and $52.9 \%$ (female $60.5 \%$ and male $45.3 \%$ ) agreed that the donors are temporarily weekend. $4.5 \%$ students (female $1 \%$ and male $7.9 \%$ ) strongly agreed and $23.1 \%$ (female $21.5 \%$ and male $24.6 \%$ ) agreed that they donate blood to get free investigation. 
Table 4: Positive attitude towards blood donation of MBSTU students.

\begin{tabular}{|c|c|c|c|}
\hline \multirow[b]{2}{*}{ Variables } & \multicolumn{3}{|c|}{ Responders sex } \\
\hline & $\begin{array}{l}\text { Female } \\
\text { n }(\%)\end{array}$ & $\begin{array}{l}\text { Male n } \\
(\%)\end{array}$ & $\begin{array}{l}\text { Total n } \\
(\%)\end{array}$ \\
\hline \multicolumn{4}{|c|}{ Q1: I think blood donation saves life. } \\
\hline Strongly agree & $\begin{array}{l}116 \\
(28.8)\end{array}$ & $\begin{array}{l}137 \\
(67.5)\end{array}$ & $\begin{array}{l}253 \\
(62.8)\end{array}$ \\
\hline Agree & $70(35)$ & $59(29.1)$ & $129(32)$ \\
\hline Neutral & $10(5)$ & $4(2)$ & $14(3.5)$ \\
\hline Disagree & $3(1.5)$ & $1(0.5)$ & $4(1)$ \\
\hline Strongly disagree & $1(0.5)$ & $2(1)$ & $3(0.7)$ \\
\hline \multicolumn{4}{|c|}{ Q2: I think blood donation is a moral activity. } \\
\hline Strongly agree & $104(52)$ & $126(62.1)$ & $230(57.1)$ \\
\hline Agree & $88(44)$ & $63(31)$ & $151(37.5)$ \\
\hline Neutral & $5(2.5)$ & $10(4.9)$ & $15(3.7)$ \\
\hline Disagree & $3(1.5)$ & $4(2)$ & $7(1.7)$ \\
\hline Strongly disagree & $0(0)$ & $0(0)$ & $0(0)$ \\
\hline \multicolumn{4}{|c|}{$\begin{array}{l}\text { Q3: I think young people should frequently donate } \\
\text { blood rather than old. }\end{array}$} \\
\hline Strongly agree & $88(44)$ & $73(36)$ & $161(40)$ \\
\hline Agree & $88(44)$ & $110(54.2)$ & $198(49.1)$ \\
\hline Neutral & $18(9)$ & $15(7.4)$ & $33(8.2)$ \\
\hline Disagree & $5(2.5)$ & $4(2)$ & $9(2.2)$ \\
\hline Strongly disagree & $1(0.5)$ & $1(0.5)$ & $2(0.5)$ \\
\hline \multicolumn{4}{|c|}{$\begin{array}{l}\text { Q4: I think people having more knowledge on blood } \\
\text { donation donate more often. }\end{array}$} \\
\hline Strongly agree & $35(17.5)$ & $32(15.8)$ & $67(16.6)$ \\
\hline Agree & $118(59)$ & $94(46.3)$ & $212(52.6)$ \\
\hline Neutral & $30(15)$ & $50(24.6)$ & $80(19.9)$ \\
\hline Disagree & $16(8)$ & $18(8.9)$ & $34(8.4)$ \\
\hline Strongly disagree & $1(0.5)$ & $9(4.4)$ & $10(2.5)$ \\
\hline \multicolumn{4}{|c|}{$\begin{array}{l}\text { Q5: In my opinion the best way to donate blood is } \\
\text { voluntary non-remunerated. }\end{array}$} \\
\hline Strongly agree & $53(26.5)$ & $37(18.2)$ & $90(22.3)$ \\
\hline Agree & $93(46.5)$ & $74(36.5)$ & $167(41.4)$ \\
\hline Neutral & $46(23)$ & $78(38.4)$ & $124(30.8)$ \\
\hline Disagree & $6(3)$ & $11(5.4)$ & $17(4.2)$ \\
\hline Strongly disagree & $2(1)$ & $3(1.5)$ & $15(1.2)$ \\
\hline \multicolumn{4}{|c|}{$\begin{array}{l}\text { Q6: I think every person should always disclose correct } \\
\text { information about his/her health before donate blood. }\end{array}$} \\
\hline Strongly agree & $106(53)$ & $83(40.9)$ & $189(46.9)$ \\
\hline Agree & $69(34.5)$ & $65(32)$ & $134(33.3)$ \\
\hline Neutral & $14(7)$ & $41(20.2)$ & $55(13.6)$ \\
\hline Disagree & $10(5)$ & $10(4.9)$ & $20(5)$ \\
\hline Strongly disagree & $1(0.5)$ & $4(2)$ & $5(1.2)$ \\
\hline
\end{tabular}

$\mathrm{n}=$ number of study participants

\section{Positive attitude towards blood donation}

Table 4 demonstrates the positive attitudes of female and male study participants about blood donation. The analyses revealed that $62.8 \%$ students (female $28.8 \%$ and male $67.5 \%$ ) strongly agreed and $32 \%$ (female $35 \%$ and male $29.1 \%$ ) agreed that blood donation saves lives. $57.1 \%$ students (female $52 \%$ and male $62.1 \%$ ) strongly agreed and $37.5 \%$ (female $44 \%$ and male $31 \%$ ) agreed that blood donation is a moral activity. $40 \%$ students (female $44 \%$ and male $36 \%$ ) strongly agreed and $49.1 \%$ (female $44 \%$ and male $54.2 \%$ ) agreed that young people should frequently donate blood rather than elderly $16.6 \%$ students (female $17.5 \%$ and male $15.8 \%$ ) strongly agreed and $52.6 \%$ (female $59 \%$ and male $46.3 \%$ ) agreed that people having more knowledge on blood donation, donate more often. $22.3 \%$ students (female $26.5 \%$ and male $18.2 \%$ ) strongly agreed and $41.4 \%$ (female $46.5 \%$ and male $36.5 \%$ ) agreed that best way to donate blood is voluntary non-remunerated. $46.9 \%$ students (female $53 \%$ and male $40.9 \%$ ) strongly agreed and $33.3 \%$ (female $34.5 \%$ and male $32 \%$ ) agreed that blood donors should always disclose correct information about their health before blood donation.

Table 5: Practice on blood donation among female and male students of MBSTU.

\begin{tabular}{|c|c|c|c|c|}
\hline \multirow[b]{2}{*}{ Variables } & \multicolumn{3}{|c|}{ Responders sex } & \multirow[b]{2}{*}{$\begin{array}{l}\mathbf{p} \\
\text { value }\end{array}$} \\
\hline & $\begin{array}{l}\text { Female n } \\
(\%)\end{array}$ & $\begin{array}{l}\text { Male n } \\
(\%)\end{array}$ & $\begin{array}{l}\text { Total n } \\
(\%)\end{array}$ & \\
\hline \multicolumn{5}{|c|}{ Q1: Have you donated before? } \\
\hline Yes & $26(13)$ & $112(55.2)$ & $138(34.2)$ & \multirow{2}{*}{$0.000^{* * *}$} \\
\hline No & $174(87)$ & $91(44.8)$ & $265(65.8)$ & \\
\hline \multicolumn{5}{|c|}{ Q2: Satisfied to donate? } \\
\hline Yes & $68(34)$ & $149(73.4)$ & $217(53.8)$ & \multirow{2}{*}{$0.000^{* * *}$} \\
\hline No & $132(66)$ & $54(26.6)$ & $186(46.2)$ & \\
\hline \multicolumn{5}{|c|}{ Q3: Unfit to donate? } \\
\hline Yes & $75(37.5)$ & $35(17.2)$ & $110(27.3)$ & \multirow{2}{*}{$0.000^{* *}$} \\
\hline No & $125(62.5)$ & $168(82.8)$ & $293(72.7)$ & \\
\hline \multicolumn{5}{|c|}{$\begin{array}{l}\text { Q4: Eagerness to donate blood to their friend or relatives } \\
\text { in future? }\end{array}$} \\
\hline Yes & $175(87.5)$ & $195(96.1)$ & $370(91.8)$ & \multirow{2}{*}{$0.002^{*}$} \\
\hline No & $25(12.5)$ & $8(3.9)$ & $33(8.2)$ & \\
\hline \multicolumn{5}{|c|}{ Q5: Fear of needle? } \\
\hline Yes & $92(46)$ & $76(37.4)$ & $168(41.7)$ & \multirow{2}{*}{0.081} \\
\hline No & $108(54)$ & $127(62.6)$ & $235(58.3)$ & \\
\hline \multicolumn{5}{|c|}{ Q6: Fear of knowing my status? } \\
\hline Yes & $50(25)$ & $37(18.2)$ & $87(21.6)$ & \multirow{2}{*}{0.098} \\
\hline No & $150(75)$ & $166(81.8)$ & $316(78.4)$ & \\
\hline \multicolumn{5}{|c|}{ Q7: Donated blood may be sold? } \\
\hline Yes & $22(11)$ & $29(14.3)$ & $51(12.7)$ & \multirow{2}{*}{0.321} \\
\hline No & $178(89)$ & $174(85.7)$ & $352(87.3)$ & \\
\hline \multicolumn{5}{|c|}{ Q8: No payment? } \\
\hline Yes & $165(82.5)$ & $174(85.7)$ & $339(84.1)$ & \multirow{2}{*}{0.377} \\
\hline No & $35(17.5)$ & $29(14.3)$ & $64(15.9)$ & \\
\hline
\end{tabular}

\section{Practice on blood donation}

The Table 5 shows the blood donation practice between female and male students of MBSTU. The results showed that, more male students $(55.2 \%)$ donated blood than that of female students $(13 \%)$ and the difference is statistically 
significant ( $\mathrm{p}<0.001)$. Mental satisfaction upon blood donation were significantly $(\mathrm{p}<0.001)$ more in male than that of female student. Physically female students were more unfit for donating blood in compare to the male students and the results were statistically significant ( $p$ $<0.001$ ). $87.5 \%$ Female and $96.1 \%$ male student have eagerness to donate blood to their friend or relatives in future. Fear of needles and fear of exposing their status were more in female students than the male counterpart although the results were not statistically significant. Maximum students think that donated blood should not be sold (female $89 \%$ and male $85.7 \%$ ) and blood donation should be voluntary (female $82.5 \%$ and male $85.7 \%$ ) without any payment.

\section{DISCUSSION}

Globally several epidemiological research groups conducted surveys on Knowledge, Attitude and Practice (KAP) to understand factors that influence adequate and safe blood donation as well as donor mobilization strategies which have been summarized by Lownik et al. ${ }^{13}$ This knowledge is helpful to establish a safe blood supply based on voluntary, non-remunerated donors in many countries across the world. There is a scarcity of research surrounding the motivational factors affecting blood donations in the developing world. In many countries, the recruitment of safe, low-risk donors is challenging. ${ }^{13}$ As far our knowledge very few research group conducted such survey in Bangladesh related to voluntary blood donation especially focusing any public university students. In near far a survey was conducted by Hosain et al, to assess the Knowledge and attitude towards voluntary blood donation among Dhaka University students in Bangladesh and as far our knowledge, in last two decades no research group has given attention on these issues. In their cross-sectional study they reported that only $16 \%$ students donate blood voluntarily. ${ }^{10}$ Our results (Table 5) showed that total $34.2 \%$ student participants donated blood voluntarily before. This indicates that voluntary blood donation practice is increasing in Bangladesh. Current study also revealed that females were attributed significantly lower $(\mathrm{p}<0.001)$ blood donation practice than male students (13\%female and $55.2 \%$ male) although the knowledge score on blood donation was significantly higher $(\chi 2=4.865 ; \mathrm{p}<0.05)$ in female than male students (Table 5). Voluntary donation practice in female is lower may be due to their unfitness to donate blood, fear of needles and fear of knowing their status. The result showed that female students were more fearful about needle (female $46 \%$ and male $37.4 \%$ ) and were more concern about knowing their status than male students (female $25 \%$ and male $18.2 \%$ ), although the results were not statistically significant. Also females were significantly unsatisfied upon blood donation ( $\mathrm{p}<0.001)$ (Table 5). This figure is similar to studies conducted on medical students in Pakistan, India and China. ${ }^{14-16}$ In agreement with our results, females were less likely to donate blood than males in previous studies. ${ }^{14,17,18}$
Public university students are a considerable sector of the community serves notable roles in blood donation both directly by donating blood themselves and indirectly through educating the community about the importance and safety of blood donations. Our study included a good number of student participants from all 15 departments of MBSTU among which 200 were female and 203 were male. The university is a science and technology university where almost all students except two departments have science background and it is expected to have sufficient knowledge on blood donation. Our results were also consistent with the agreement and we have found total $59.06 \%(n=238)$ students have good knowledge about blood donation (Table 2).

In the study all participants knew their own blood group. Knowing blood group here is a admission criteria of all students and they have to mention it for preparing their identity cards. Distribution of blood group among male and female of the study participants are mentioned in figure 1. The results showed that Both in male and female students, highest number of participants had B positive blood group ( $45.2 \%$ in female and $31 \%$ in male). In female, next came were $\mathrm{O}$ positive, $\mathrm{A}$ positive, $\mathrm{AB}$ positive, $\mathrm{O}$ negative, $\mathrm{AB}$ negative and $\mathrm{B}$ negative. In case of male, next came were $O$ positive, $A$ positive, $A B$ positive, $\mathrm{O}$ negative, $\mathrm{B}$ negative, $\mathrm{A}$ negative and $\mathrm{AB}$ negative.

The study revealed that Maximum proportion of students agreed that blood donation saves lives and blood donation is a moral activity and young people should frequently donate blood rather than elderly. They also agreed that people having more knowledge on blood donation, donate more often and they thought the best way to donate blood is voluntary non-remunerated (Table 4). and these results are in consistent with some literature reports. ${ }^{10,17,19}$ Having positive attitudes among maximum students, negative attitudes on voluntary blood donation were not uncommon among MBSTU students. Some believe that the best way to donate blood is at the request of relatives, donation in paid or something in exchange, blood donor contract disease upon donation and donors may be temporarily weakened upon donation (Table 3).

It is also reported that, a large part of the blood supply is obtained from first-time donors many of whom are students. However, the transmissible disease-positive test rate is much lower in repeat donors and thus, increasing the proportion of repeat donors is an important step in improving the supply and safety of the blood. ${ }^{15}$

There are several limitations in this study that warrant further discussion. The study design cannot assess the cause and effect relationship. In addition, the factors expected to influence knowledge, attitude and practice may not be exhaustive. There could be other factors, which the study did not reveal. It has to be noted that the finding of this study mainly reflects the situation in Mawlana 
Bhashani Science and Technology University. Therefore, the findings should be interpreted with caution.

\section{ACKNOWLEDGEMENTS}

The authors are thankful to the department of Biotechnology and Genetic Engineering of MBSTU for giving permission to conduct the study. We would like to thank all the students participated in this study and giving their valuable time to complete the study.

\section{Funding: No funding sources}

Conflict of interest: None declared

Ethical approval: The study was approved by the Department of Biotechnology and Genetic Engineering (BGE) of Mawlana Bhashani Science and Technology University (MBSTU), Bangladesh

\section{REFERENCES}

1. Fordham J, Dhingra N. Towards $100 \%$ voluntary blood donation: a global framework for action. World Health Organization, Geneva; 2010.

2. World Health Organization. Global Status Report on Blood Safety and Availability 2016, 2017. Available at:

http://apps.who.int/iris/bitstream/handle/10665/25498 7/9789241565431-

eng.pdf;jsessionid=3D2EE3CD2E079D6ABD89E24 05BEDD969? sequence $=1$ ]

3. Alanazi MT, Elagib H, Aloufi HR, Alshammari BM, Alanazi SM, Alharbi SF, et al. Knowledge attitude and practice of blood donation in Hail University. Int $\mathrm{J}$ of Com Med Public Health. 2018 Feb 24;5(3):846-55.

4. World Health Organization. Voluntary unpaid blood donations must increase rapidly to meet 2020 goal. Saudi Med J. 2016 Jul 5;37(7):819-20.

5. Gibbs WN, Corcoran P. Blood safety in developing countries. Vox sanguinis. 1994 Nov 1;67(4):377-81.

6. Available https://www.thedailystar.net/backpage/number-

blood-donors-rise-1419814 [accessed on 1 may 2018]

7. World Health Organization. Blood transfusion safety. Switzerland: WHO. 2006:7-10.

8. Nigatu A, Demissie DB. Knowledge, attitude and practice on voluntary blood donation and associated factors among Ambo University Regular Students, Ambo Town, Ethiopia. J Community Med Health Educ. 2014;4(5):6.

9. Zubair H, Seema HS. Comparative study on knowledge attitude and practice regarding blood donation in rural and urban area of Bangalore. Int $\mathrm{J}$ of Med and Heal Scienc. 2015;4(3):309-14.
10. Hosain GM, Anisuzzaman M, Begum A. Knowledge and attitude towards voluntary blood donation among Dhaka University students in Bangladesh. East Afr Med J. 1997 Sep;74(9):549-53.

11. Gebresilase HW, Fite RO, Abeya SG. Knowledge, attitude and practice of students towards blood donation in Arsi university and Adama science and technology university: a comparative cross sectional study. BMC hematology. 2017 Dec;17(1):20.

12. Urgesa K, Hassen N, Seyoum A. Knowledge, attitude, and practice regarding voluntary blood donation among adult residents of Harar town, Eastern Ethiopia: a community-based study. J of Blo Medici. 2017;8:13.

13. Lownik E, Riley E, Konstenius T, Riley W, McCullough J. Knowledge, attitudes and practices surveys of blood donation in developing countries. Vox sanguinis. 2012 Jul 1;103(1):64-74.

14. Ahmed Z, Zafar M, Khan AA, Anjum MU, Siddiqui MA. Knowledge, attitude and practices about blood donation among undergraduate medical students in Karachi. J of Inf Diseas and Therap. 2014 Mar 29;2(2).

15. Kowsalya V, Vijayakumar R, Chidambaram R, Srikumar R, Reddy EP, Latha S, et al. A study on knowledge, attitude and practice regarding voluntary blood donation among medical students in Puducherry, India. PJBS. 2013 May;16(9):439-42.

16. Gao L, Wang Q. Survey on knowledge, attitude and practice about blood donation among continuing medical education (CME) students in Sichuan province, China. Transfusion and Apheresis Science. 2017 Jun 1;56(3):454-8.

17. Amatya M. Study on Knowledge Attitude and Practice of Blood Donation among Students of Different Colleges of Kathmandu Nepal. Int $\mathbf{J}$ of Pharmaceut and Biologi Archiv. 2013 Oct 5;4(3).

18. Wiwanitkit V. A study on attitude towards blood donation among people in a rural district, Thailand. Southeast Asian J Trop Med Public Health. 2000;31(3):609-11.

19. Wiwanitkit V. Knowledge about blood donation among a sample of Thai university students. Vox Sang. 2002;83(2):97-9.

Cite this article as: Hossain MI, Easmin N, Rahman S, Islam M, Salam A. Knowledge, attitude and practice regarding voluntary blood donation among Mawlana Bhashani Science and Technology University students in Bangladesh. Int J Basic Clin Pharmacol 2018;7:1464-70. 